\title{
CEN: Understanding Rook vs Minor Piece Endgames
}

Article

Accepted Version

Haworth, G. (2020) CEN: Understanding Rook vs Minor Piece Endgames. ICGA Journal, 42 (1). pp. 41-45. ISSN 1389-6911 doi: https://doi.org/10.3233/ICG-190140 Available at https://centaur.reading.ac.uk/88727/

It is advisable to refer to the publisher's version if you intend to cite from the work. See Guidance on citing.

Published version at: https://content.iospress.com/articles/icga-journal/icg190140

To link to this article DOI: http://dx.doi.org/10.3233/ICG-190140

Publisher: The International Computer Games Association

All outputs in CentAUR are protected by Intellectual Property Rights law, including copyright law. Copyright and IPR is retained by the creators or other copyright holders. Terms and conditions for use of this material are defined in the End User Agreement.

\section{www.reading.ac.uk/centaur}

\section{CentAUR}

Central Archive at the University of Reading

Reading's research outputs online 


\title{
CEN: Understanding Rook vs Minor Piece Endgames
}

\author{
Guy Haworth ${ }^{1}$ \\ Reading, UK
}

There is major chess endgame news to kick off the New Year, indeed the 2020 'decade of vision'. The established and leading endgame team of Karsten Mūller and Yakov Konoval $(2016,2018,2019)$ have produced the third volume of their 'Understanding Endgames' series, this time Understanding Rook vs Minor Piece Endgames, here URME. As GM Alex Fishbein says in his eloquent foreword, this is an ideal way for players and fans at all levels to get to know and love these three pieces and understand their relative strengths and weaknesses in opposition and in combination.

The chosen domain once again excludes the queens but they will surely dominate the court some time soon like Queen Elizabeth I and Lady Macbeth. URME falls neatly with a now obvious logic into four parts, easily discernible if not explicitly expressed on the 'Contents' page:

1: KRP* KmP*: 'Rook vs one minor piece', ' $\mathrm{P}^{*}$ ' indicating 0 - $n$ pawns,

Ch. 1) KRP*KNP*: rook vs knight,

Ch. 2) KRP*KBP*: rook vs bishop including Timman-Velimirovic (1979).

2: KRP*KmmP': 'Rook vs two minor pieces',

Ch. 3) KRP*KNNP*: rook vs two knights, building on Troitzky's KNNKP,

Ch. 4) KRP*KBBP*: rook vs two bishops inc. Kasparov-Kramnik (2000),

Ch. 5) KRP*KBNP*: rook vs bishop and knight inc. Carlsen-Aronian (2012).

3: $\mathrm{KRmP}^{*} \mathrm{KRP}^{*}$ : rook and minor piece vs rook:

Ch. 6) KRNP*KRP*: rook and knight vs rook inc. Polgar-Kasparov (1996),

Ch. 7) KRBP*KRP*: rook and bishop vs rook inc. Philidor's win and defences.

4: Ch. 8) KRmP*KRmP*: rook and minor piece vs rook and minor piece, N/N, B/B, B/N.

An introduction relates the history, from the late 1970s, of creating 7-man 'EGT' endgame tables and highlights the exemplary work of Yakov Konoval and Marc Bourzutschky in creating and verifying the 'DTC' Depth to Conversion EGTs used here. Your reviewer is sadly old enough to remember the pre-history which includes the work of Bellman (1965), Ströhlein (1970) ${ }^{2}$, and Komissarchik \& Futer $(1974)^{3}$. URME derives its towering authority not only from the well-known and leading insight of Karsten Mūller but also from the factual accuracy of endgame tables, both Yakov's DTC EGTs and occasionally the 'Syzygy' DTZ 50 " EGTs (de Man et al, 2018).

The book clearly encourages the reader to walk before they run, focusing purely on the head-to-head between the rook and one minor piece. What we are calling 'Part 1' here is the first half of the book and includes 56 of the 108 exercises for the reader. All its content theoretically comes within range

\footnotetext{
${ }^{1}$ Communicating author: g.haworth@ reading.ac.uk

${ }^{2} 2020$ is the $50^{\text {th }}$ anniversary of Ströhlein's thesis which followed his 1967-9 computations on the AEG-Telefunken TR4.

It deserves to be more accessible and more widely known. Help with the German and/or graph theory is welcome.

${ }^{3}$ A noble achievement for the time but ignored underpromotions and is slightly flawed (Thompson, 1986, pp. 136-7).
} 
of FINALGEN (Romero, 2012) as there is no more than one piece on either side. Readers will be able to investigate the cited positions of lesser mobility with this software. The often-sought asymmetry of rook vs minor piece is the natural result when one side sacrifices the exchange for some anticipated strategic, positional advantage.
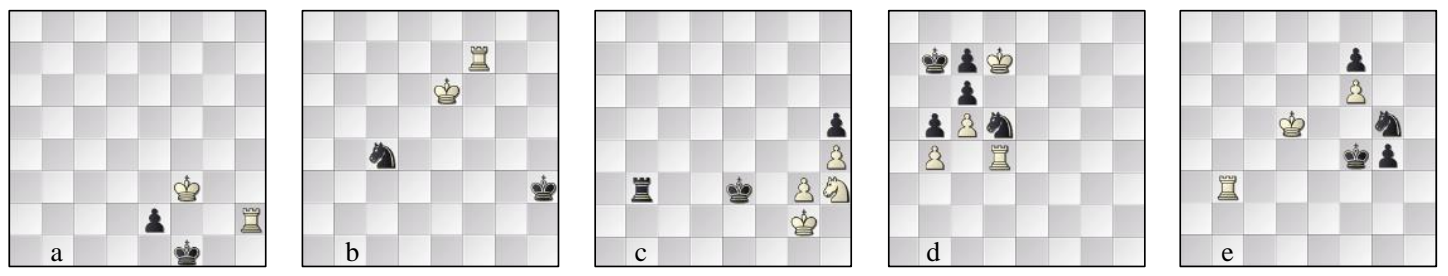

Fig. 1. (a) \#1.04, Kamsky-Bacrot, 74...e1=N+= but lost later; (b) \#1.05, Karpov-Ftacnik, domination and zugzwang; (c) \#1.18, Javakhishvili-Khurtsidze (2011), missed fortress, 60. Nf4?? (60. Ng5! needed);

(d) \#1.26, Carlsen-Aronian (2012), btm, fortress draw; (e) \#1.44, Zubarev-Ponomariov (2001), 57...g3!, 0-1.

Chapter 1 sees the finely carved knight in the fight after being unaccountably missing from the book's cover, see Fig. 7. However, it is first exposed as a Falstaff or Don Quixote rather than as a hero, staggeringly slow on foot, ironically lacking a horse, able to jump a little in the dance if unable to change feet. We start with KRKN, defensible if not always defended even at GM level, and sometimes arising from the forced knighting of a pawn as in Fig. 1a. The rook can dominate the shortwinded knight and use zugzwang as a weapon as from Fig. 1b. The battle extends through KRPKN and KRPKNP where the pawns' file-status - blocking, neighbourly or 'passed' - is key as in UME. Finally, we see the Knight redeemed - manning fortresses in KRP*KNP*, Fig. 1c and 1d, and even putting the rook's side on the defensive with the help of a pawn majority, Fig. 1e.
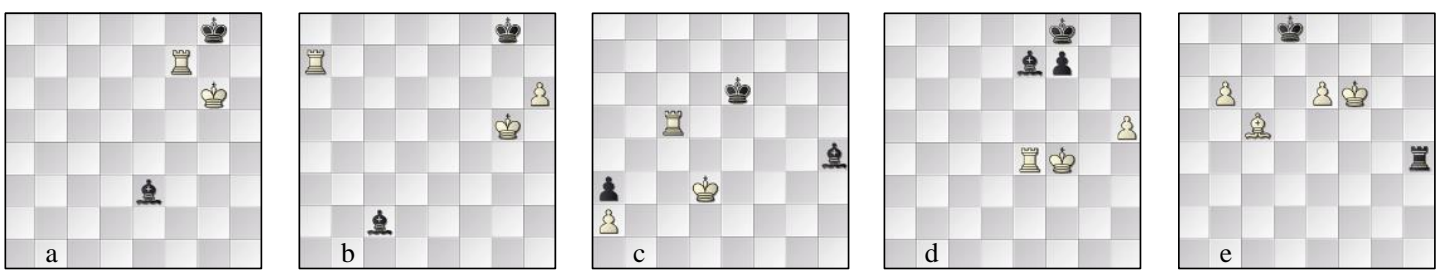

Fig. 2. (a) \#2.02, Breyer-Tarrasch (1920), wrong corner, 1-0; (b) \#2.05, right corner example, fortress draw;

(c) \#2.21, Timman-Velimirovic (1979) 64b (wtm 1-0, btm =), lost after 68...Kf8?? when $d t c=36$ moves;

(d) \#2.33, Ding Liren - Bu Xiangzhi (2009) 79b (wtm 1-0, btm =), lost after 94...Kh6?? (Bg5 essential);

(e) \#2.74, Monier-Bitelmajer (2003), 56w, 56. e7 but not 56. b7?? Kc7!! 57. e7 Rh8 58. Kg7 Re8!!=.

Chapter 2 changes the music as the knight gives way to the bishop - a piece of diagonal perspective, half actor, half influencer and best accompanied by a complementary bishop covering its weaknesses as in Chapter 4. The pilgrimage is similar to the crusade of the previous chapter: the almost drawn KRKB (Fig. 2a), KRPKB (Fig. 2b) - and KRPKBP including the fascinating KRP(a2)KBP(a3) endgame of Timman-Velimirovic (Chéron, 1969; Donner, 2006; Mūller and Haworth, 2013; Timman, $2011, \ldots)$. This position inspired nights of ultimately triumphant insight, post hoc theory and extensive EGT computation (van den Herik et al, 1987), all high points of analysis visible far and wide. Fig. $2 c$ is merely a doorway to the comprehensive literature. Of course, elsewhere as in Figs. $2 \mathrm{~d}$ and $2 \mathrm{e}$, supported by enough acolyte pawns, the bishop can still theoretically, if not in practice, survive in a 'right corner' fortress or even come out on top. 
In Chapter 3, the rook first plays for the win with the help of two connected or close passed pawns. Then it is the two knights' turn to attack, even while flirting with the 50-move rule as in Fig. 3a. Here the URME-adjacent 'Troitzky' KNNKP endgame is used to establish some ideas. Moving on, chapter 4 demonstrates that two bishops normally have the advantage over a rook as in Fig. $3 \mathrm{~b}$ but the balance can be delicate and the play subtle. Fishbein notes that a rook and two connected passed pawns fare better against two bishops than against the bishop and knight of Chapter 5 .
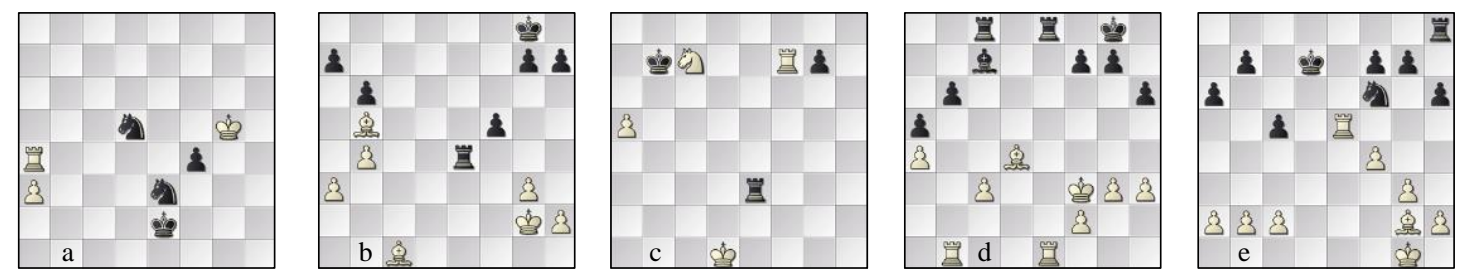

Fig. 3. (a) \#3.14, Galliamova-Danielian, (wtm =, btm 0-1 in 90 moves), 72...f3!! 73. Rh4! Ng2? (f2 better) but won; (b) \#4.18, Short-Alekseev, 1-0; (c) \#6.06, Kramnik-Kasparov, CWC London 2000, 54...Re5?!=, a missed win later; (d) \#8.05; Carlsen-Caruana (2012), Carlsen wins 'with the better bishop and more active king';

(e) \#8.12, Fischer-Taimanov (1971), 24...b6? 'weakens the light squares too much' 25. Bf1!, 1-0 as analysed.

Part 3 sees the rook flanked by a minor piece as is often the case on the board. Nunn (1994) was the first to use the sub-6-man EGTs of Thompson (1986) on a major scale. He covered the important endgames KRNKR and KRBKR, the latter the battlefield of the Philidor attack, the Cochrane Defense and some of the longest games on record. Here, pawns join in as in Fig. 3c. The natural finale of $\mathrm{KRm}_{1} \mathrm{P}^{*} \mathrm{KRm}_{2} \mathrm{P}^{*}$, previously under-represented in the literature, divides neatly into three obvious parts: $\mathrm{m}_{1} \mathrm{~m}_{2} \equiv$ the joust $\mathrm{NN}$, the 'Carlsen endgame' BB and the 'Fischer endgame' (perhaps because of \#8.12, Fig. 3e) BN. The reputation of opposite-colour-bishop endgames is restored, see for example Fig. 3d. Pawns may be used to avoid or block the opposing bishop.
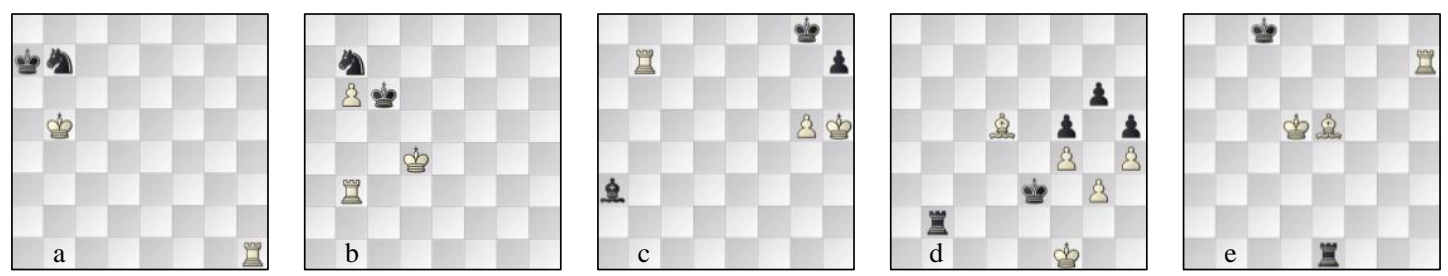

Fig. 4. Five studies, all wtm: (a) \#1.03, Al Adli ( $9^{\text {th }}$ Century CE), 1-0, the knight falls in 11 moves;

(b) \#1.06, Berger (1922), =, but correct defence found by Frink (1927); (c) \#2.25, Elkies (1993), an instructive 1-0; (d) \#2.61, Kholmov (1973), 'an important method', 1-0; (e) E7.01, Nunn (1995), 1-0.

Fig. 4 is a selection of five favourite studies from the database of van der Heijden (2015). Many studies have become exemplar demonstrations of winning themes. Chapter 9 lists eight 7 -man studies that were cooked en passant under the spotlight of EGT-truth. The final pages include the extensive, annotated solutions to the exercises and useful indexes of featured players, study composers and longest wins. It is a pleasure to see some famous names of the game's early history alongside those of today's top grandmasters. Notably, Magnus Carlsen's entry is more than twice as long as anyone else's: his endgame prowess, growing the smallest advantages, is well known.

Longest 'maxDTC' wins literally illustrate the depth of Chess and its most balanced contests. There are just twelve of them in URME, perhaps because the early moves of many deep wins are mysterious rather than instructive. Fig. 6 provides five exercises for the reader. The final footnote includes some solutions and comments. The e-version of this article (Haworth, 2020) complements the book with a 
file of Yakov's maxDTC wins and DTC-minimaxing lines for all 120 endgames in this domain. It also includes a pgn file with full coverage of the examples here.
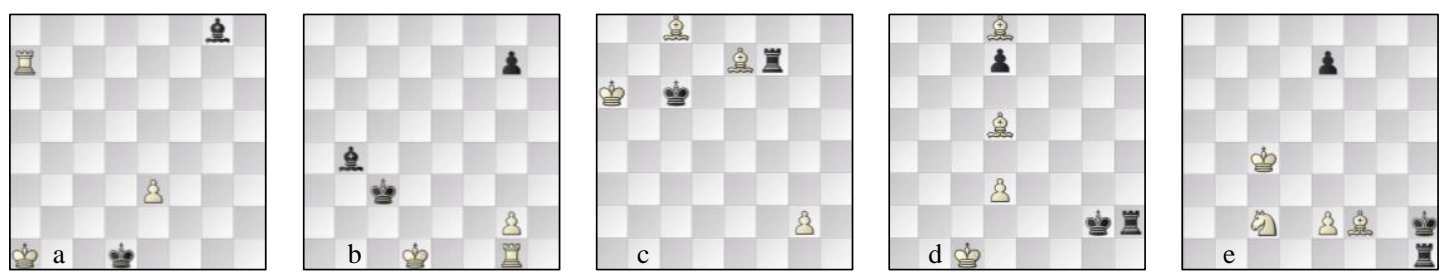

Fig. 5. Five maxDTC 1-0 wins: (a) \#2.09, KRPKB btm, $d t c / z 50^{\prime}=62 / 35 \mathrm{~m}^{4}$;

(b) \#2.36, KRPKBP btm, dtc/z50' = 99/31 m; three 50mr draws ... (c) \#4.10, KBBPKR wtm, $d t c / z 50^{\prime}=167 / 132 \mathrm{~m}$;

(d) \#4.17, KBBPKRP btm, $d t c / z 50^{\prime}=169 / 92 \mathrm{~m}$; (e) \#5.32, KBNPKRP wtm, $d t c / z_{50} 0^{\prime}=181 / 1 \mathrm{~m}^{5}$
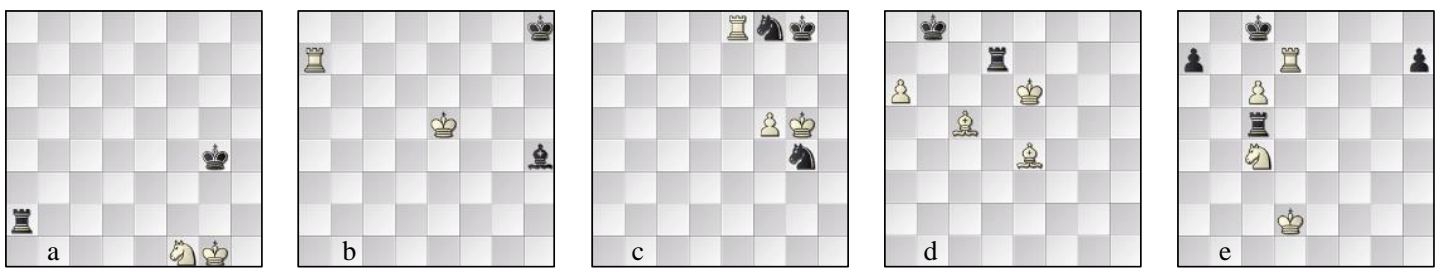

Fig. 6. Exercises: (a) \#E1.02, Ganguly-Ringoir (2014), wtm and draw; (b) \#E2.01, Platov (1925), wtm and win; (c) \#E3.01, Velimirovic-Ivanisevic (1998), btm and draw;

(d) \#E4.01, Holzke-Tolnai (1992), White's winning move?; (e) \#E6.01, Sokolov-Colutiis (2011), wtm and win.

Understanding Rook vs Minor Piece Endgames is a handsome volume and another extraordinary corpus of state-of-the-art endgame analysis. At the same time, throughout the text, it generously credits previous work in this domain: there is also an opening bibliography where we find particular focus on names such as Dvoretsky (2003) and Nunn (1994, 2002). URME is a very welcome addition to the definitive 'Understanding Endgames' series of books which have each explored a tractable slice of the chess endgame thematically and with great structure and clarity. Once again, 'kudos' and congratulations to the authors: their benchmark standard has been maintained.

\section{REFERENCES}

Bellman, R. E. (1965). On the Application of Dynamic Programming to the Determination of Optimal Play in Chess and Checkers. PNAS, Vol. 53(2), pp. 244-247, doi: 10.1073/pnas.53.2.244.

Chéron, A. (1969). Lehr und Handbuch Der Endspiele. Vol. 1, pp. 315-329 (esp. p. 323) and Vol. 3, pp. 285-297. Siegfried Engelhardt Verlag. ASIN B0021WO8L2.

de Man, R., Guo, B. and Fiekas, N. (2018). Query interface to the sub-8-man DTZ50" EGTs.

Donner, J. H. (2006). The King, esp. pp. 319-327. The English translation of De Koning (1987). New in Chess.

Dvoretsky (2003). Dvoretsky's Endgame Manual, Russell Enterprises. $4^{\text {th }}$ edition (2014).

\footnotetext{
${ }^{4} \mathrm{DTZ}_{50}{ }^{\prime} \equiv$ Depth to 'Zeroing of the ply-count' in the context of the FIDE rule 9.2 '50mr' 50-move draw-rule: $d t c$ and $d t z_{50}{ }^{\prime}$ are depths in winner's moves in the DTC and $\mathrm{DTZ}_{50}$ ' metrics respectively.

${ }^{5}$ Black defends the 50mr draw by timely advances of the e-pawn with first phases of, e.g., 1, 36, 89 and 16 moves. maxDTC in the URME domain is KRNPKRB's 265 moves.
} 
Haworth, G. $M^{\mathrm{c} C}$. (2020). http://centaur.reading.ac.uk/86555/. This article with supporting pgn file covering the 25 cited positions.

Komissarchik E. A. and Futer, A. L. (1974). Об анализе ферзевого эндшпиля при помощи ЭВМ. (Ob Analize Ferzevogo Endshpilya pri Pomoshchi EVM. Analysis of a queen endgame using an IBM computer.) Проблемы кибернетики (Problemy Kybernetiki), 29, pp. 211-220. Republished in English by Posthoff and Herschberg as 'Computer Analysis of a Queen Endgame', ICCA Journal, 9(4), 189-198 (1986).

Mūller, K. and Haworth, G. (2013). Rook versus Bishop. ICGA Journal, 36 (4). pp. 195-202.

Mūller, K. and Konoval, Y. (2016). 'URE': Understanding Rook Endgames. Gambit.

Mūller, K. and Konoval, Y. (2018). 'UME': Understanding Minor Piece Endgames. Russell.

Mūller, K. and Konoval, Y. (2019). Understanding Rook vs Minor Piece Endgames. Russell.

Nunn, J. (1994). Secrets of Pawnless Endings. Second expanded edition, Gambit (2002).

Romero, P. P. (2012). http://finalgenchess.ovh/home_ing. FINALGEN endgame table generator.

Ströhlein, T. (1970). Untersuchungen über kombinatorische Spiele. Ph.D. thesis, Technical University of Munich.

Thompson, K. (1986). Retrograde Analysis of Certain Endgames. ICCA Journal, 9(3), 131-9.

Timman, J. (2011). The Art of the Endgame, esp. Ch. 2, Rook versus Bishop. New in Chess. ${ }^{6}$

van den Herik, J., Herschberg, R. and Nakad, N. (1987). A Six-Men-Endgame Database: KRP(a2)KbBP(a3). ICCA Journal, 10(4), 163-180. See also ICCA Journal, 11(2-3) 82-91.

van der Heijden, H.M.J.F. (2015). http://www.hhdbv.nl/. HHDBV, ENDGAME STUDY DATABASE V.
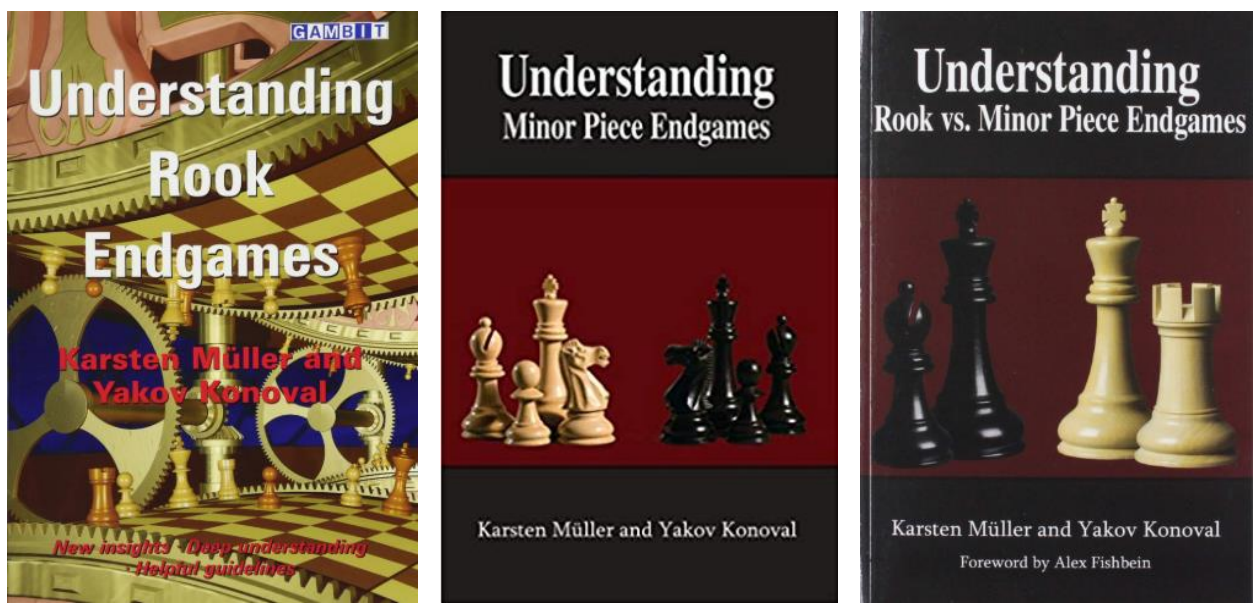

Fig. 7: The Understanding Endgames series to date: URE, UME and now URME.

\footnotetext{
${ }^{6}$ Fig. 6's exercises, solutions and comments: E1.02: Not 86. Ne3+? as played but 86. $\mathrm{Nh} 2+$ !! $\mathrm{Kg} 3$ 87. $\mathrm{Nf1} 1+$ !! =. E2.01: 1. Kf5! (not 1. Rf7? Kg8!! 2. Ke6 Bg5=) Kg8 2. Ra4! Be1 3. Kg6! Kf8 4. Rf4+! Ke7 5. Re4+! 1-0. E3.01: 80...Nh2? lost (81. Kf4 Kf7 82. Re2 Nf1 83. Rf2 ...) but 80...Kf7! 81. Ra8 Ne5 82. Ra7+ Nfd7 draws. E4.01: 82. Kf6!? and Black, in deadly zugzwang, resigned. 82 ...Rd8 83. a7 Kc7 84. a8Q; 82...Kc7 83. a7. E6.01: 53. Nd6+! Kb8 54. c7+ and Black resigned in view of 54... Rxc7 55. Rd8+! Rc8 56. Rxc8\#.
} 